\title{
The effects of vitamin $\mathrm{C}$ and nitric oxide synthase inhibition on coronary flow and oxidative stress markers in isolated rat heart
}

\author{
Vladimir Lj. Jakovljevic ${ }^{1}$, Dusica Z. Djordjevic ${ }^{1}$ and Dragan M. Djuric ${ }^{2}$ \\ ${ }^{1}$ Department of Physiology, Faculty of Medicine, University of Kragujevac, Serbia \\ ${ }^{2}$ Institute of Medical Physiology "Richard Burian", University School of Medicine, Belgrade, Serbia
}

\begin{abstract}
The aim of this study was to assess the effects of vitamin C (ascorbic acid) on coronary flow and oxidative stress markers with or without non-specific inhibition of nitric oxide synthase by $\mathrm{N}^{\omega}$-nitro-L-arginine monomethyl ester (L-NAME) in isolated rat hearts. The hearts of male Wistar albino rats ( $n=12$, age 8 weeks, body mass $180-200 \mathrm{~g}$ ) were retrograde perfused according to the Langendorff technique at gradually increased constant perfusion pressure $\left(40-120 \mathrm{~cm} \mathrm{H}_{2} \mathrm{O}\right)$. Coronary flow, nitrite outflow, superoxide anion production, and index of lipid peroxidation (by measuring thiobarbituric acid reactive substances) in coronary effluent were determined. The experiments were performed during control conditions and in presence of vitamin $C(100 \mu \mathrm{M})$ alone or vitamin C $(100 \mu \mathrm{M})+\mathrm{L}-\mathrm{NAME}(30 \mu \mathrm{M})$. Administration of vitamin C induced only increase of nitrite levels, while vitamin C + L-NAME induced significant decrease of coronary flow above autoregulatory range, i.e. especially at higher coronary perfusion pressure (CPP) values, accompanied with similar dynamic in nitrite outflow. Vitamin C + L-NAME also induced significant decrease in TBARS production. The results of our study show no significant effects of vitamin $\mathrm{C}$ administration either on ROS levels or on coronary flow in isolated rat heart.
\end{abstract}

Key words: Vitamin C - Nitric oxide - Coronary flow - Oxidative stress

\section{Introduction}

Vitamin C (ascorbic acid) is the most potent water-soluble antioxidant in human plasma (Frei et al. 1990). Due to its remarkable redox properties, ascorbate (major form of vitamin $\mathrm{C}$ at physiological $\mathrm{pH}$ ) is one of the most efficient antioxidants in cells and biological fluids (Rose and Bode 1993; Vergely et al. 2001). It readily scavenges free radicals such as superoxide anion radical, hydroxyl radical, and hypochlorous acid (Jeserich et al. 1999), regenerates vitamin E from its tocopheroxyl radical and spares intracellular glutathione (Carr and Frei 2000). This latter function may be particularly important with respect to endothelial vasodilator function because glutathione has been implicated in enhanced endothelium-derived nitric oxide (NO) synthesis and stabilization of NO through the formation of S-nitrosothiols (Carr and Frei 2000). Vitamin C has also

Correspondence to: Vladimir Lj. Jakovljevic, Department of Physiology, Faculty of Medicine, University of Kragujevac, Svetozara Markovica 69, P.O.Box 124, 34000 Kragujevac, Serbia

E-mail: drvladakgbg@yahoo.com been implicated in the release of NO from S-nitrosothiols (Scorza et al. 1997).

The effects of ascorbic acid on the bioactivity of endothelium-derived NO have been extensively studied in humans and to a lesser extent in experimental animals (Tomasian et al. 2000). It was demonstrated that ascorbic acid reverse endothelial dysfunction in patients with numerous diseases (Levine et al. 1996; Ting et al. 1996; Motoyama et al. 1997; Hornig et al. 1998; Taddei et al. 1998; Teramoto et al. 2004; de Sousa et al. 2005; Grebe et al. 2006; Hernández-Guerra et al. 2006; Cangemi et al. 2007). These remarkably consistent findings prompt studies to elucidate the mechanism of this beneficical effect of ascorbic acid on the bioactivity of endothelium-derived NO.

Cellular damage caused by reactive oxygen species (ROS) such as superoxide anion radicals $\left(\mathrm{O}_{2}^{-}\right)$or hydroxyl radicals $\left(\mathrm{OH}^{-}\right)$is a significant causal factor involved in heart diseases, especially during myocardial ischemia-reperfusion (Vergely et al. 2001). Many authors have provided extensive evidence that free radicals are produced and released from the ischemic heart and that their production is especially intensive in the reperfusion period (Blasig et al. 1994; Dhalla 
et al. 2000; Guaiquil et al. 2004). Rapid restoration of the blood flow increases the level of tissue oxygenation which causes the second burst of ROS generation that leads to the reperfusion injury (Maxwell and Lipp 1997). One of the possible mechanisms of ROS-mediated cardiovascular diseases is lowering the levels of vasodilatory substances produced in the endothelium (Ajay and Mustafa 2006), among which NO is the most important (Gewaltig and Kojda 2002).

The aim of this experimental study was to assess the effects of vitamin $\mathrm{C}$ on the coronary flow, oxidative stress markers and nitrites with or without non-specific nitric oxide synthase (NOS) inhibition by $\mathrm{N}^{\omega}$-nitro-L-arginine monomethyl ester (L-NAME) in isolated rat hearts.

\section{Materials and Methods}

\section{Isolated rat heart preparation}

The hearts (total number $n=12,6$ hearts for each experimental group; discarded hearts were not included in the total number of the hearts) excised from Wistar male albino rats, 8 weeks old, with body mass of about $200 \mathrm{~g}$ (obtained from Military Medical Academy, Belgrade, Serbia) were perfused with Langendorff apparatus (Hugo Sachs Elektronik-Harvard Aparatus GmbH, March-Hugstetten, Germany). After short-term ether narcosis, animals were killed by cervical dislocation (Schedule 1 of the Animals/Scientific Procedures, Act 1986, UK), with heparin premedication as an anticoagulant. After urgent thoracotomy and rapid heart arrest by superfusion with ice-cold isotonic saline, the hearts were rapidly excised, isolated, the aortas were cannulated and retrograde perfused according to the technique for constant pressure conditions. The composition of the nonrecirculating Krebs-Henseleit perfusate was as follows (in mmol/l): $\mathrm{NaCl} 118, \mathrm{KCl} 4.7, \mathrm{CaCl}_{2} \times 2 \mathrm{H}_{2} \mathrm{O} 2.5, \mathrm{MgSO}_{4} \times$ $7 \mathrm{H}_{2} \mathrm{O} 1.7, \mathrm{NaHCO}_{3} 25, \mathrm{KH}_{2} \mathrm{PO}_{4} 1.2$, glucose 11, pyruvate 2, equilibrated with $95 \% \mathrm{O}_{2}+5 \% \mathrm{CO}_{2}$ and warmed to $37^{\circ} \mathrm{C}$ ( $\mathrm{pH} 7.4)$. All hearts were electrically paced (5 V, $320 \mathrm{bpm})$ by the electric stimulator (Hugo Sachs Elektronik-Harvard Aparatus $\mathrm{GmbH}$ ) and constant left ventricular draining through the dissected mitral valve was performed.

\section{Physiological assay}

After the heart perfusion had been set up, a 30 min period was allowed for stabilization of the preparation. Stabilization of preparation was performed at basal coronary perfusion pressure of $60 \mathrm{~cm} \mathrm{H}_{2} \mathrm{O}$. In order to test coronary vascular reactivity, all hearts were challenged by short-term occlusions (5-30 s), as well as by bolus injection of $5 \mathrm{mmol} / \mathrm{l}$ adenosine $(60 \mu \mathrm{l}$ at a flow rate of $10 \mathrm{ml} / \mathrm{min}$ in order to elicit maximal coronary flow). The hearts were discarded (about 25\%) if the flow did not increase by $100 \%$ over the control value (for both tests). After the equilibration period, coronary perfusion pressure was lowered to 50 and $40 \mathrm{~cm}$ $\mathrm{H}_{2} \mathrm{O}$ and then gradually increased to $70,80,90,100,110$ and $120 \mathrm{~cm} \mathrm{H}_{2} \mathrm{O}$ in order to establish coronary autoregulation. When the flow was considered as stable at each value of perfusion pressure, samples of the coronary effluent were collected. Properly performed control experiments included studying of the coronary perfusion pressure/coronary flow relationship twice in the absence of any drug. It was essential to confirm that the used preparation was stable and that the responses to the first and the second run of changes in perfusion pressure did not differ substantially. After performing the control experimental protocol, the hearts were perfused with ascorbic acid $(100 \mu \mathrm{M})$ and with ascorbic acid $(100 \mu \mathrm{M})$ plus an inhibitor of NO synthesis, (30 $\mu \mathrm{M}$ of L-NAME) for minimum. Test period started immediately after control experiments in order to avoid time-dependent adverse effects. Drug administration was performed until stable flow was reached but not less then 5 minutes at each perfusion pressure. Data (coronary flow, levels of superoxide anion radical, nitrites and index of lipid peroxidation) obtained during control experimental protocol was compared with data obtained after vitamin $\mathrm{C}$ or vitamin C + L-NAME perfusion.

\section{Biochemical assays}

Samples of the coronary venous effluent were collected after the stabiliation of flow at each value of gradually increased perfusion pressure. Spectrophotometric method was used for determination of nitrite, superoxide anion radical and index of lipid peroxidation.

\section{Nitrite determination}

Nitric oxide decomposes rapidly to form stable metabolite nitrite/nitrate products. Nitrite was determined and used as an index of nitrite oxide production by the spectrophotometric method using the Griess's reagent. $0.5 \mathrm{ml}$ of perfusate was precipitated with $200 \mu \mathrm{l}$ of $30 \%$ sulfosalicylic acid, vortexed for $30 \mathrm{~min}$ and centrifuged at $3000 \times \mathrm{g}$. Equal volumes of the supernatant and Griess's reagent, containing $1 \%$ sulfanilamide in $5 \%$ phosphoric acid $/ 0.1 \%$ napthalene ethylenediamine-dihydrochloride was added and incubated for $10 \mathrm{~min}$ in the dark and read at $543 \mathrm{~nm}$ of wavelength. The nitrite levels were calculated by using sodium nitrite as a standard (Green et al. 1982).

\section{Superoxide anion radical determination}

The level of $\mathrm{O}_{2}^{-}$was measured using Nitro blue tetrazolium (NBT) reaction in TRIS-buffer with coronary venous efflu- 
ent and read at $530 \mathrm{~nm}$ of wavelength. Krebs-Hensenleit solution was used as a blank probe (Auclair and Voisin 1985).

Index of lipid peroxidation (Thiobarbituric acid reactive substances - TBARS)

The degree of lipid peroxidation in coronary venous effluent was estimated by measuring of TBARS using $1 \%$ Thiobarbituric acid (TBA) in $0.05 \mathrm{NaOH}$ incubated with coronary effluent at $100^{\circ} \mathrm{C}$ for 15 minutes and read at $530 \mathrm{~nm}$. KrebsHensenleit solution was used as a blank probe (Ohkawa et al. 1979).

\section{Drugs}

The provider of L-NAME, spectrophotometric assay kit (used for nitrite determination), napthalene ethylenediamine-dihydrochloride as well as sulfosalicylic acid was from Sigma-Aldrich Chemie $\mathrm{GmbH}$, while vitamin C (ascorbic acid) was purchased from Galenika AD (Belgrade, Serbia). Sulfanilamide, phosphoric acid, NBT, Tris-Buffer and TBA were purchased from Merck KGaA (Darmstadt Germany).

\section{Statistical analysis}

Values are expressed as means \pm S.E.M. Statistical analysis was performed by multifactorial analysis of variance for repeated measurements between subject factors as well as Bonferroni's test; $p$ values less than 0.05 were considered to be significant.

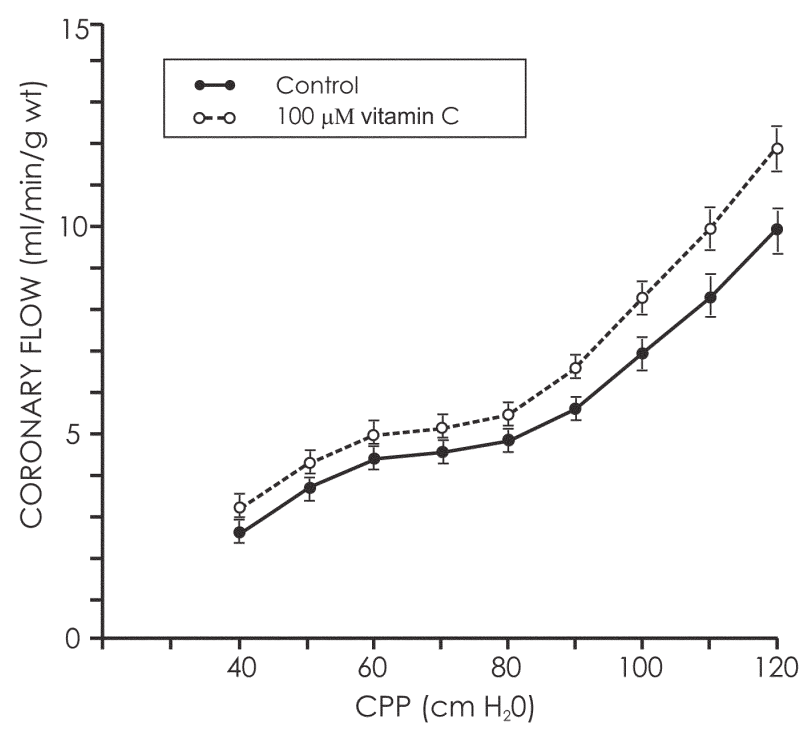

\section{Results}

Coronary flow

Coronary flow increased proportionally to coronary perfusion pressure in the whole range of perfusion pressure studied both in control and study groups. During control conditions coronary flow varied in range from $2.68 \pm 0.51 \mathrm{ml} / \mathrm{min} / \mathrm{g}$ weight of tissue (wt) at $40 \mathrm{~cm} \mathrm{H}_{2} \mathrm{O}$ to $9.65 \pm 0.93 \mathrm{ml} / \mathrm{min} / \mathrm{g}$ wt at $120 \mathrm{~cm} \mathrm{H}_{2} \mathrm{O}$ (Fig. 1, left). Vitamin $\mathrm{C}$ did not induce significant change in coronary flow (Fig. 1, left). On the other hand, vitamin C + L-NAME induced significant decrease of coronary flow above autoregulatory range, i.e. at higher coronary perfusion pressure (CPP) values (Fig. 1, right).

\section{Nitrite outflow}

During control conditions nitrite outflow varied from $0.63 \pm$ $0.18 \mathrm{nmol} / \mathrm{min} / \mathrm{g}$ wt at $40 \mathrm{~cm} \mathrm{H}_{2} \mathrm{O}$ to $2.71 \pm 0.74 \mathrm{nmol} / \mathrm{min} / \mathrm{g}$ wt at $120 \mathrm{~cm} \mathrm{H}_{2} \mathrm{O}$ and was parallel with $\mathrm{CPP}$ - coronary flow curve (Fig. 2, left). Vitamin $\mathrm{C}$ induced significant increase in nitrite outflow $\left(0.93 \pm 0.21 \mathrm{nmol} / \mathrm{min} / \mathrm{g}\right.$ wt at $40 \mathrm{~cm} \mathrm{H}_{2} \mathrm{O}$ to $3.72 \pm 1.09 \mathrm{nmol} / \mathrm{min} / \mathrm{g}$ wt at $120 \mathrm{~cm} \mathrm{H} \mathrm{H}_{2} \mathrm{O}$ ) (Fig. 2, left). Vitamin C + L-NAME induced significant reduction of the nitrite outflow from $18 \%$ at $40 \mathrm{~cm} \mathrm{H}_{2} \mathrm{O}$ to $37 \%$ at $120 \mathrm{~cm}$ $\mathrm{H}_{2} \mathrm{O}$ (Fig. 2, right).

\section{Superoxide anion production}

During control conditions superoxide anion radical production varied from $9.92 \pm 1.43 \mathrm{nmol} / \mathrm{min} / \mathrm{g}$ wt at $40 \mathrm{~cm} \mathrm{H}_{2} \mathrm{O}$ to

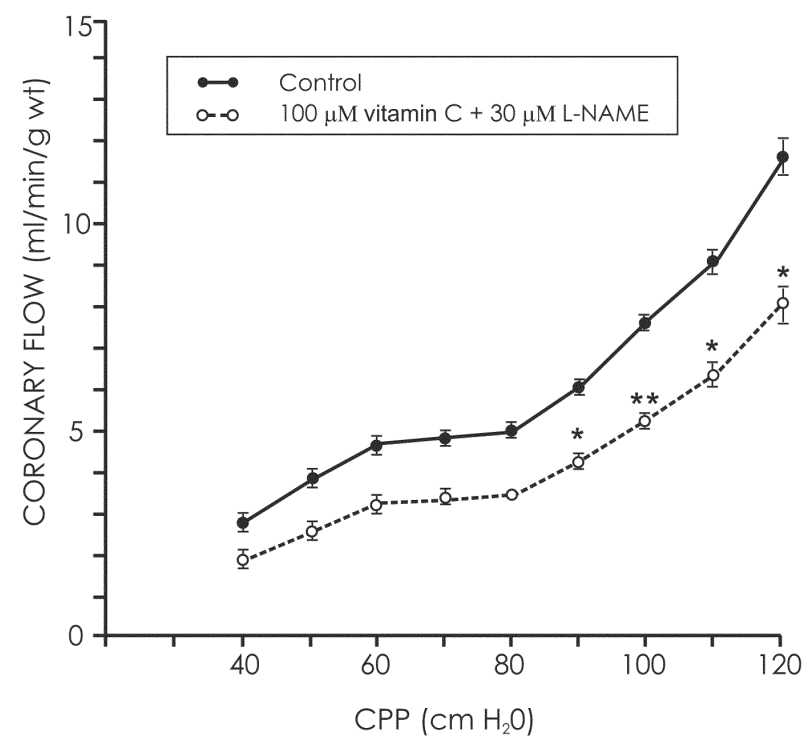

Figure 1. Coronary flow values $(\mathrm{ml} / \mathrm{min} / \mathrm{g} w \mathrm{wt})$ at different coronary perfusion pressure $(\mathrm{CPP})$ values $\left(\mathrm{cm}_{2} \mathrm{O}\right)$ in vitamin $\mathrm{C}$-treated group (left) and in vitamin C+L-NAME-treated group (right). ${ }^{*} p<0.05,{ }^{* *} p<0.01$. 

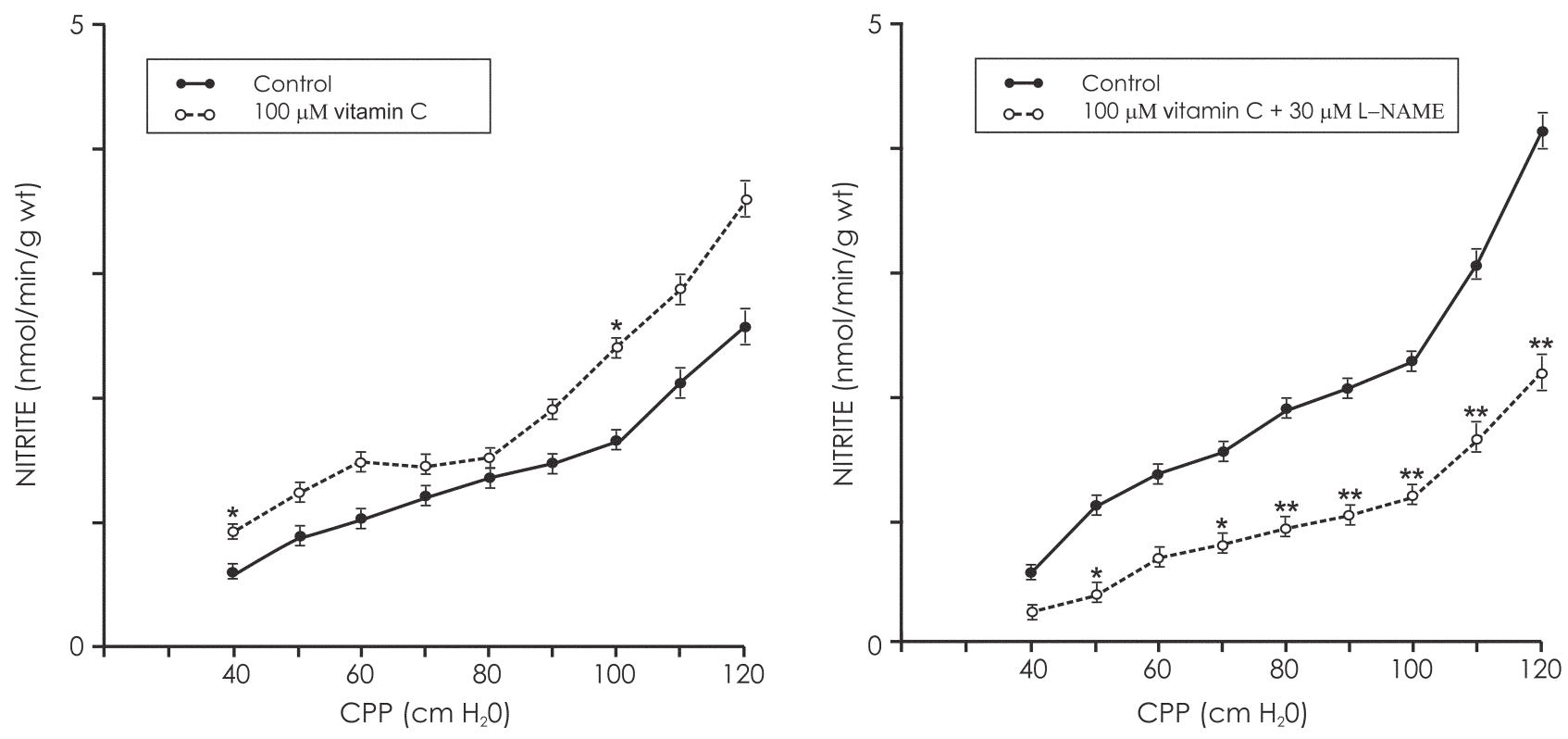

Figure 2. Nitrite outflow (nmol/min/g wt) in coronary venous effluent at different coronary perfusion pressure $(\mathrm{CPP})$ values $\left(\mathrm{cm} \mathrm{H}_{2} \mathrm{O}\right)$ in vitamin C-treated group (left) and in vitamin C+L-NAME-treated group (right). ${ }^{\star} p<0.05,{ }^{* *} p<0.01$.

$28.89 \pm 1.34 \mathrm{nmol} / \mathrm{min} / \mathrm{g}$ wt at $120 \mathrm{~cm} \mathrm{H}_{2} \mathrm{O}$ and was parallel with CPP- coronary flow curve (Fig. 2, left). Vitamin C did not induce significant changes in $\mathrm{O}_{2}{ }^{-}$levels. (Fig. 3, left). Vitamin C + L-NAME also did not change significantly superoxide anion production compared with control values (Fig. 3, right).

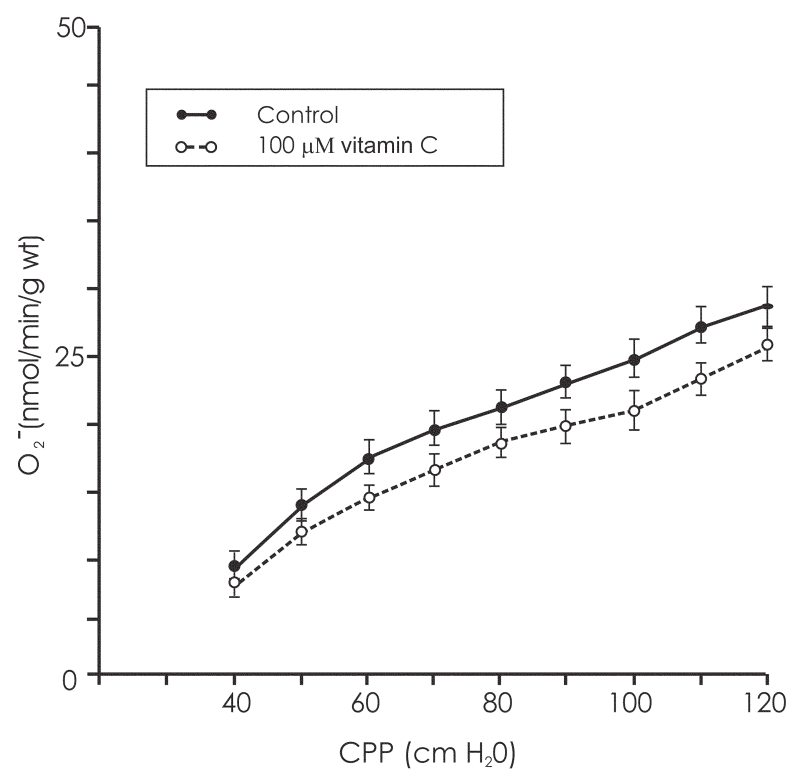

Index of lipid peroxidation (TBARS production)

During control conditions TBARS production varied from $0.91 \pm 0.26 \mu \mathrm{mol} / \mathrm{min} / \mathrm{g}$ wt at $40 \mathrm{~cm} \mathrm{H}_{2} \mathrm{O}$ to $2.46 \pm$ $1.35 \mu \mathrm{mol} / \mathrm{min} / \mathrm{g}$ wt at $120 \mathrm{~cm} \mathrm{H}_{2} \mathrm{O}$ and was parallel with CPP- coronary flow curve (Fig. 4, left). Vitamin C did not

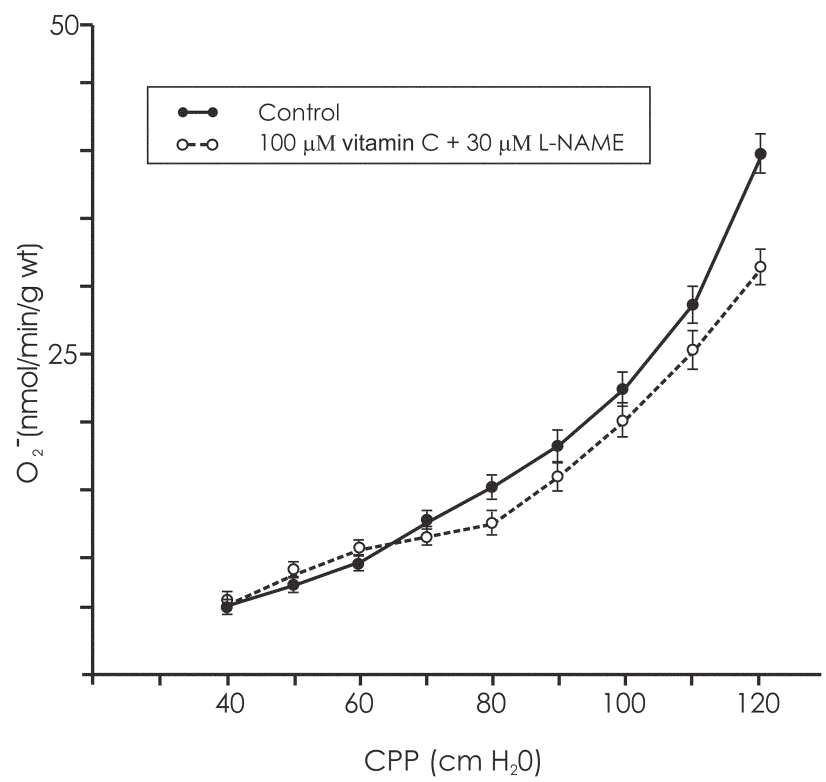

Figure 3. Superoxide anion production ( $\mathrm{nmol} / \mathrm{min} / \mathrm{g} \mathrm{wt}$ ) in coronary venous effluent at different coronary perfusion pressure (CPP) values $\left(\mathrm{cm} \mathrm{H}_{2} \mathrm{O}\right)$ in vitamin C-treated group (left) and in vitamin $\mathrm{C}+\mathrm{L}-\mathrm{NAME}$-treated group (right). 
change significantly TBARS production at any CPP-value (Fig. 4, left). On the other hand, vitamin C + L-NAME significantly decreased TBARS production compared with control values (from $8 \%$ at $40 \mathrm{~cm} \mathrm{H}_{2} \mathrm{O}$ to $37 \%$ at $120 \mathrm{~cm}$ $\mathrm{H}_{2} \mathrm{O}$ (Fig. 4, right).

\section{Discussion}

In this study, the vascular effects of acute vitamin $\mathrm{C}$ or vitamin $\mathrm{C}+\mathrm{L}-\mathrm{NAME}$ (NOS inhibitor) administration in the isolated rat hearts at various CPP values were studied. The coronary flow, production of nitrites (as a marker of NO) and production of oxidative stress markers (superoxide anion radical and TBARS) were estimated. Data (coronary flow, levels of $\mathrm{NO}_{2}{ }^{-}, \mathrm{O}_{2}{ }^{-}$and TBARS) obtained at each CPP value after vitamin $\mathrm{C}$ or vitamin $\mathrm{C}+\mathrm{L}-\mathrm{NAME}$ administration were compared with data obtained in the control conditions. The differences in the levels of investigated parameters in certain groups of animals in the control conditions are due to reason of biological diversity.

After administration of vitamin $\mathrm{C}$ alone, the only statistically significant change in investigated parameters was found in $\mathrm{NO}\left(\mathrm{NO}_{2}^{-}\right)$levels (the increase of $\mathrm{NO}_{2}{ }^{-}$levels), while administration of vitamin $\mathrm{C}+\mathrm{L}-\mathrm{NAME}$ induced the decrease of three parameters - coronary flow, $\mathrm{NO}_{2}{ }^{-}$and TBARS. The presented data are different to folic acid-induced effects on the same experimental model (Djuric et al. 2007). In contrast to vitamin $\mathrm{C}$, which induced only the rise in $\mathrm{NO}_{2}^{-}$levels, folic acid induced the significant increase in both $\mathrm{NO}_{2}{ }^{-}$levels and coronary flow, and decreased $\mathrm{O}_{2}^{-}$levels. TBARS also increased after folic acid administration, which is a bit contradictory to changes of superoxide production (Djuric et al. 2007). Furthermore, effects of in vitamin C + L-NAME administration were significantly different than effects of folic acid + L-NAME administration which induced no significant changes in any of the investigated parameters. The results regarding TBARS levels are unexpected since $\mathrm{O}_{2}{ }^{-}$levels were unchanged after vitamin $\mathrm{C}+\mathrm{L}-\mathrm{NAME}$ administration.

Given the importance of superoxide anion radical as a mechanism of endothelial dysfunction in atherosclerosis and the role of lipid peroxidation as a mechanism of impaired bioactivity of endothelium-derived NO in atherosclerosis (Tomasian et al. 2000; Kawashima and Yokoyama 2004), many authors assumed that ascorbic acid exerts its beneficial effects by scavenging superoxide anion and inhibiting lipid peroxidation (Levine et al. 1996; Ting et al. 1996). Another suggested mechanism by which ascorbic acid improves bioactivity of endothelium-derived NO is by influencing cellular redox state (Tomasian et al. 2000). There is evidence that ascorbic acid spares intracellular glutathione from oxidation thus increasing its availability which is important in both NO experimental models (Ghigo et al. 1993; Gorren et al. 1997; Zaidi et al. 2005) and in human subjects (Kugiyama et al. 1998; Prasad et al. 1999). Furthermore, there is evidence that vitamin $C$ may have direct effects on activity of NOS, possibly through an effect on tetrahydrobiopterin (Heller et al. 1999; Huang et al. 2000; Förstermann and Münzel 2006). Heller et al.
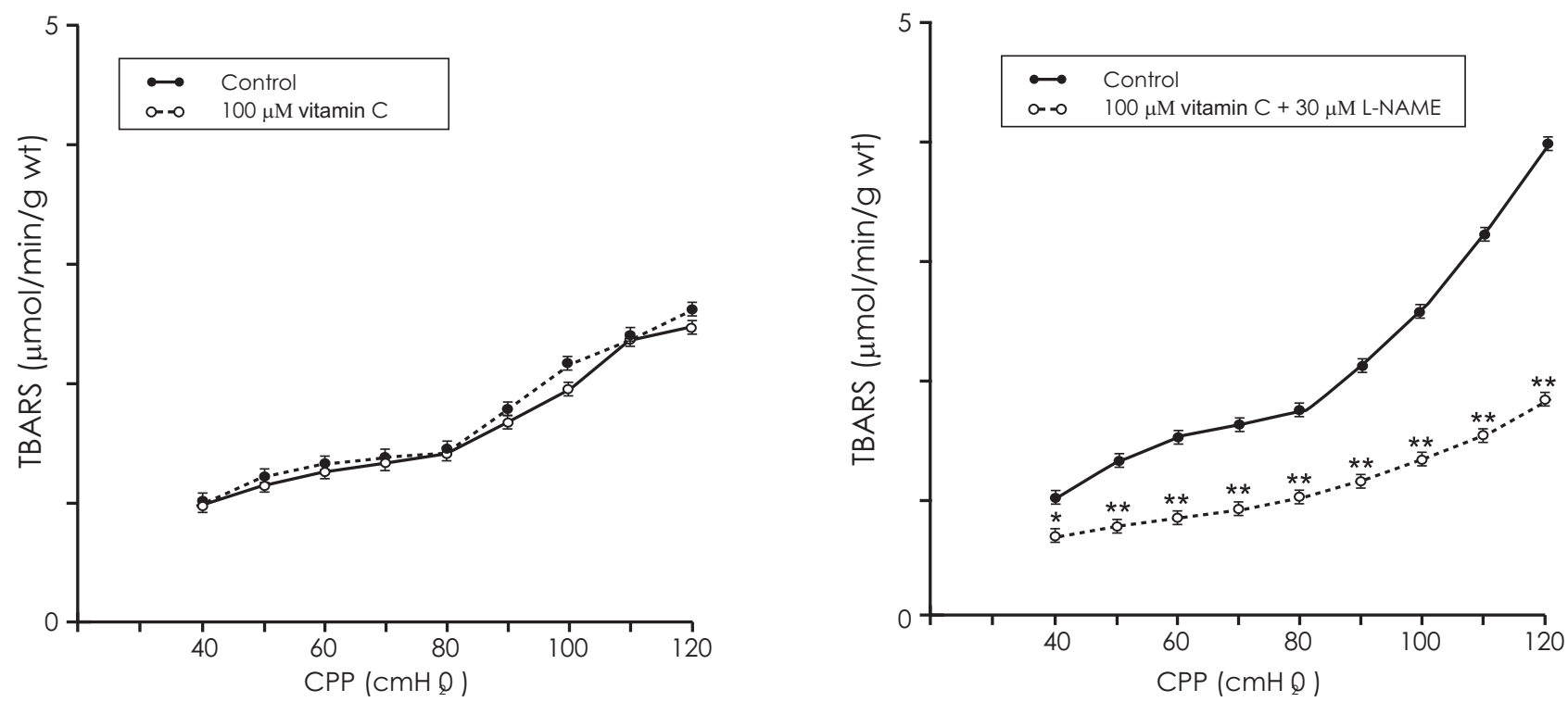

Figure 4. TBARS production ( $\mu \mathrm{mol} / \mathrm{min} / \mathrm{g} \mathrm{wt})$ in coronary venous effluent at different coronary perfusion pressure $(\mathrm{CPP})$ values $(\mathrm{cm}$ $\mathrm{H}_{2} \mathrm{O}$ ) in vitamin C-treated group (left) and in vitamin $\mathrm{C}+\mathrm{L}-\mathrm{NAME}$-treated group (right). ${ }^{*} p<0.05,{ }^{* *} p<0.01$. 
(1999) investigated the effects of vitamin C (0.1-100 mM) on the synthesis of NO by cultured human coronary artery and umbilical vein endothelial cells, and found that vitamin $\mathrm{C}$ increases the production of both citrulline, the byproduct of NO synthesis, and cyclic GMP, a marker of NO bioactivity. The authors implicated modulation by vitamin $\mathrm{C}$ of the availability or affinity of tetrahydrobiopterin to NOS as a possible mechanism for the observed increase in endothelium-derived NO synthesis. This vitamin C effect on NO production is evident at physiologically relevant extracellular and intracellular concentrations of ascorbic acid (Heller et al. 1999; Huang et al. 1999), while it was suggested that the superoxide anion scavenging mechanism might explain improved NO action only in studies that involved intra-arterial infusion of supraphysiological concentrations of ascorbic acid (Heitzer et al. 1996; Ting et al. 1996; Solzbach et al. 1997; Taddei et al. 1998), not following acute or chronic administration of physiological doses of ascorbic acid (Levine et al. 1996; Motoyama et al. 1997; Chambers et al. 1999). The results of our study (the absence of vitamin $\mathrm{C}$ effects on either $\mathrm{O}_{2}{ }^{-}$and TBARS levels or coronary flow) suggest that a mechanism other than $\mathrm{O}_{2}{ }^{-}$scavenging or flow-mediated $\mathrm{NO}$ increase was responsible for the increase in NO levels in isolated heart. One of the possible mechanisms may be the increase of dimeric form of NO synthase.

Although administration of vitamin $\mathrm{C}$ increased levels of $\mathrm{NO}\left(\mathrm{NO}_{2}{ }^{-}\right)$, coronary flow was not increased compared with flow in the control conditions. On the other hand, administration of vitamin $\mathrm{C}+\mathrm{L}-\mathrm{NAME}$ induced the fall in $\mathrm{NO}_{2}{ }^{-}$level which was followed by the fall in coronary flow. These effects are probably fully caused by L-NAME, since we previously showed that addition of the L-NAME alone induces significant fall in levels of nitrites and coronary flow (Jakovljevic and Djuric 2005). Furthermore, the decrease of TBARS level by vitamin C + L-NAME addition could reflect rather negative $\mathrm{NO}$ effect (production of peroxynitrites), especially after increasing perfusion pressure. It is demonstrated also by "opening scissors" between control and vitamin C + L-NAME TBARS levels and respective coronary perfusion pressure.

The limitations of our study are: 1) the heart rate and heart contractility were not registered; 2) the concentrations of DHA and $\mathrm{OH}^{-}$were not measured in coronary venous effluent; 3 ) the real time measurement of various free radicals in tissue bath solutions was not performed; 4) concentration-response curves for vitamin C and LNAME could not be obtained at all CPP values in this experimental model, taking into consideration long duration of such experiments and a great possibility to cause the heart injury (usual L-NAME concentration for the isolated heart was found from $0.3 \mu \mathrm{M}$ to $300 \mu \mathrm{M}$ and for vitamin $\mathrm{C}$ from $10 \mu \mathrm{M}$ to $100 \mu \mathrm{M})$.
Although it was suggested that a loss of vitamin $\mathrm{C}$ tissue availability might impair its ability to counterbalance increased ROS production, as observed during post-ischemic reperfusion in the heart (Haramaki et al. 1998; Guaiquil et al. 2004) and that administration of exogenous antioxidants would improve recovery (Shuter et al. 1990), the results of our study clearly showed no significant effects of vitamin C administration either on ROS levels or on coronary flow in isolated rat heart.

Acknowledgement. This work was supported by grant No.175043 of the Ministry of Science and Technological Development of Republic of Serbia. We thank Slovak Academy of Sciences (Bratislava, Slovakia) for kind L-NAME donation. The authors are very thankfull to Mr. Predrag Ravic and Mr. Andreja Petrovic for their excellent technical assistance.

\section{References}

Ajay M., Mustafa M. R. (2006): Effects of ascorbic acid on impaired vascular reactivity in aortas isolated from age-matched hypertensive and diabetic rats. Vascul. Pharmacol. 45, 127-133 doi:10.1016/j.vph.2006.05.001

Auclair C., Voisin E. (1985): Nitroblue tetrazolium reduction. In: Handbook of Methods for Oxygen Radical Research. (Ed. R. A. Greenwald), pp. 123-132, CRC Press, Boca Raton, Florida

Blasig I. E., Shuter S., Garlick P., Slater T. (1994): Relative timeprofile for free radical trapping, coronary flow, enzyme leakage, arrhythmias, and function during myocardial reperfusion. Free Radic. Biol. Med. 16, 35-41 doi:10.1016/0891-5849(94)90240-2

Cangemi R., Angelico F., Loffredo L., Del Ben M., Pignatelli P., Martini A., Violi F. (2007): Oxidative stress-mediated arterial dysfunction in patients with metabolic syndrome: Effect of ascorbic acid. Free Radic. Biol. Med. 43, 853-859 doi:10.1016/j.freeradbiomed.2007.06.002

Carr A., Frei B. (2000): The role of natural antioxidants in preserving the biological activity of endothelium-derived nitric oxide. Free Radic. Biol. Med. 28, 1806-1814 doi:10.1016/S0891-5849(00)00225-2

Chambers J. C., McGregor A., Jean-Marie J., Obeid O. A., Kooner J. S. (1999): Demonstration of rapid onset vascular endothelial dysfunction after hyperhomocysteinemia: an effect reversible with vitamin C therapy. Circulation 99, 1156-1160

de Sousa M. G., Yugar-Toledo J. C., Rubira M., Ferreira-Melo S. E., Plentz R., Barbieri D., Consolim-Colombo F., Irigoyen M. C., Moreno H. Jr. (2005): Ascorbic acid improves impaired venous and arterial endothelium-dependent dilation in smokers. Acta Pharmacol. Sin. 26, 447-452 doi:10.1111/j.1745-7254.2005.00069.x

Dhalla N. S., Temsah R. M., Netticadan T. (2000): Role of oxidative stress in cardiovascular diseases. J. Hypertens. 18, 655-673 doi:10.1097/00004872-200018060-00002

Djuric D., Vusanovic A., Jakovljevic V. (2007): The effects of folic acid and nitric oxide synthase inhibition on coronary flow 
and oxidative stress markers in isolated rat heart. Mol. Cell. Biochem. 300, 177-183 doi:10.1007/s11010-006-9381-6

Förstermann U., Münzel T. (2006): Endothelial nitric oxide synthase in vascular disease: from marvel to menace. Circulation 113, 1708-1714 doi:10.1161/CIRCULATIONAHA.105.602532

Frei B., Stocker R., England L., Ames B. N. (1990): Ascorbate: the most effective antioxidant in human blood plasma. Adv. Exp. Med. Biol. 264, 155-163

Gewaltig M. T., Kojda G. (2002): Vasoprotection by nitric oxide: mechanisms and therapeutic potential. Cardiovasc. Res. 55, 250-260 doi:10.1016/S0008-6363(02)00327-9

Ghigo D., Alessio P., Foco A., Bussolino F., Costamagna C., Heller R., Garbarino G., Pescarmona G. P., Bosia A. (1993): Nitric oxide synthesis is impaired in glutathione-depleted human umbilical vein endothelial cells. Am. J. Physiol. 265, C728-732

Gorren A. C., Schrammel A., Schmidt K., Mayer B. (1997): Thiols and neuronal nitric oxide synthase: complex formation, competitive inhibition, and enzyme stabilization. Biochemistry 36, 4360-4366 doi:10.1021/bi962381s

Grebe M., Eisele H. J., Weissmann N., Schaefer C., Tillmanns H., Seeger W., Schulz R. (2006): Antioxidant vitamin C improves endothelial function in obstructive sleep apnea. Am. J. Respir. Crit. Care Med. 173, 897-901 doi:10.1164/rccm.200508-1223OC

Green L. C., Wagner D. A., Glogowski J., Skipper P. I., Wishnok J. S., Tannenbaum S. R. (1982): Analysis of nitrate, nitrite and $[15 \mathrm{~N}]$ nitrate in biological fluids. Anal. Biochem. 126, 131-138 doi:10.1016/0003-2697(82)90118-X

Guaiquil V. H., Golde D. W., Beckles D. L., Mascareno E. J., Siddiqui M. A. Q. (2004): Vitamin C inhibits hypoxia-induced damage and apoptotic signaling pathways in cardiomyocytes and ischemic hearts. Free Radic. Biol. Med. 37, 1419-1429 doi:10.1016/j.freeradbiomed.2004.06.041

Haramaki N., Stewart D. B., Aggarwal S., Ikeda H., Reznick A. Z., Packer L. (1998): Networking antioxidants in the isolated rat heart are selectively depleted by ischemia-reperfusion. Free Radic. Biol. Med. 25, 329-339 doi:10.1016/S0891-5849(98)00066-5

Heitzer T., Just H., Munzel T. (1996): Antioxidant vitamin C improves endothelial dysfunction in chronic smokers. Circulation 94, 6-9

Heller R., Munscher-Paulig F., Grabner R., Till U. (1999): L-Ascorbic acid potentiates nitric oxide synthesis in endothelial cells. J. Biol. Chem. 274, 8254-8260 doi:10.1074/jbc.274.12.8254

Hernández-Guerra M., García-Pagán J. C., Turnes J., Bellot P., Deulofeu R., Abraldes J. G., Bosch J. (2006): Ascorbic acid improves the intrahepatic endothelial dysfunction of patients with cirrhosis and portal hypertension. Hepatology 43, 485-491 doi: $10.1002 /$ hep. 21080

Hornig B., Arakawa N., Kohler C., Drexler H. (1998): Vitamin C improves endothelial function of conduit arteries in patients with chronic heart failure. Circulation 97, 363-368
Huang A., Vita J. A., Venema R. C., Keaney J. F. Jr. (2000): Ascorbic acid enhances endothelial nitric-oxide synthase activity by increasing intracellular tetrahydrobiopterin. J. Biol. Chem. 275, 17399-17406 doi:10.1074/jbc.M002248200

Jakovljevic V. Lj., Djuric. D. M. (2005): The effects of nitric oxide synthase versus lipoxygenase inhibition on coronary flow and nitrite outflow in isolated rat heart. Gen. Physiol. Biophys. 24, 199-207

Jeserich M., Schindler T., Olschewski M., Unmuessig M., Just H., Solzbach U. (1999): Vitamin C imroves endothelial function of epicardial coronary arteries in patients with hypercholesterolemia or essential hypertension - assessed by cold pressor testing. Eur. Heart. J. 20, 1676-1680 doi:10.1053/euhj.1999.1689

Kawashima S., Yokoyama M. (2004): Dysfunction of endothelial nitric oxide synthase and atherosclerosis. Arterioscler. Thromb. Vasc. Biol. 24, 998-1005 doi:10.1161/01.ATV.0000125114.88079.96

Kugiyama K., Ohgushi M., Motoyama T., Hirashima O., Soejima H., Misumi K., Yoshimura M., Ogawa H., Sugiyama S., Yasue H. (1998): Intracoronary infusion of reduced glutathione improves endothelial vasomotor response to acetylcholine in human coronary circulation. Circulation 97, 2299-2301

Levine G. N., Frei B., Koulouris S. N., Gerhard M. D., Keaney J. F. Jr., Vita J. A. (1996): Ascorbic acid reverses endothelial vasomotor dysfunction in patients with coronary artery disease. Circulation 96, 1107-1113

Maxwell S. R., Lip G. Y. (1997): Reperfusion injury: a review of the pathophysiology, clinical manifestations and therapeutic options. Int. J. Cardiol. 58, 95-117 doi:10.1016/S0167-5273(96)02854-9

Motoyama T., Kawano H., Kugiyama K., Hirashima O., Ohgushi M., Yoshimura M., Ogawa H., Yasue H. (1997): Endothelium-dependent vasodilation in the brachial artery is impaired in smokers: effect of vitamin C. Am. J. Physiol. 273, H1644-1650

Ohkawa H., Ohishi N., Yagi K. (1979): Assay for lipid peroxides in animal tissues by thiobarbituric acid reaction. Anal. Biochem. 95, 351-358 doi:10.1016/0003-2697(79)90738-3

Prasad A., Andrews N. P., Padder F. A., Husain M., Quyyumi A. A. (1999): Glutathione reverses endothelial dysfunction and improves nitric oxide bioavailability. J. Am. Coll. Cardiol. 34, 507-514 doi:10.1016/S0735-1097(99)00216-8

Rose R. C., Bode A. M. (1993): Biology of free radical scavengers: an evaluation of ascorbate. FASEB J. 7, 1135-1142

Scorza G.; Pietraforte D.; Minetti M. (1997): Role of ascorbate and protein thiols in the release of nitric oxide from S-nitroso-albumin and S-nitroso-glutathione in human plasma. Free Radic. Biol. Med. 22, 633-642 doi:10.1016/S0891-5849(96)00378-4

Shuter S., Davies M., Garlick P., Hearse D., Slater T. (1990): Studies on the effects of antioxidants and inhibitors of radical generation on free radical production in the reperfused rat heart using electron spin resonance spectroscopy. Free Radic. Res. Commun. 9, 223-232 doi:10.3109/10715769009145680 
Solzbach U., Hornig B., Jeserich M., Just H. (1997): Vitamin C improves endothelial dysfunction of epicardial coronary arteries in hypertensive patients. Circulation 96, 1513-1519

Taddei S., Virdis A., Ghiadoni L., Magagna A., Salvetti A. (1998): Vitamin C improves endothelium-dependent vasodilation by restoring nitric oxide activity in essential hypertension. Circulation 97, 2222-2229

Teramoto K., Daimon M., Hasegawa R., Toyoda T., Sekine T., Kawata T., Yoshida K., Komuro I. (2004): Acute effect of oral vitamin $\mathrm{C}$ on coronary circulation in young healthy smokers. Am. Heart J. 148, 300-305 doi:10.1016/j.ahj.2004.03.006

Ting H. H., Timimi F. K., Boles K. S., Creager S. J., Ganz P., Creager M. A. (1996): Vitamin C improves endothelium-dependent vasodilation in patients with non-insulin-dependent diabetes mellitus. J. Clin. Invest. 97, 22-28 doi:10.1172/JCI118394
Tomasian D., Keaney J. F., Vita J. A. (2000): Antioxidants and the bioactivity of endothelium-derived nitric oxide. Cardiovasc. Res. 47, 426-435 doi:10.1016/S0008-6363(00)00103-6

Vergely C., Perrin C., Laubriet A., Oudot A., Zeller M., Guillan J.C., Rochette L. (2001): Postischemic myocardial recovery and oxidative stress status of vitamin $\mathrm{C}$ deficient rat hearts. Cardiovasc. Res. 51, 89-99 doi:10.1016/S0008-6363(01)00247-4

Zaidi S. M., Al-Qirim T. M., Banu N. (2005): Effects of antioxidant vitamins on glutathione depletion and lipid peroxidation induced by restraint stress in the rat liver. Drugs R. D. 6, $157-165$

doi:10.2165/00126839-200506030-00004

Received: January 8, 2011

Final version accepted: March 8, 2011 